\title{
DIE VERENIGDE STATE VAN AMERIKA EN SUID-AFRIKA
}

I

Die bedrywighede van die mens in Suid-Afrika is oor die eeue deur die burgers van baie lande beïnvloed en gevorm. Ontdekkingsreise, handel en kolonisasie het byvoorbeeld Portugese, Nederlanders, Engelse en Franse na die onherbergsame kuste van ons Suidland gebring. Net nadat Diaz die Stormkaap omseil het, het Columbus die eilandegordel voor die Amerikaanse kuste en 'n groot kontinent aan Europa bekend gestel. Hierdie nuwe land na die verre noordweste van Suid-Afrika, wat in sekere opvallende opsigte parallel met Suid-Afrikaanse hoofstrominge ontwikkel het, en wie se lotgevalle terselfdertyd so verskillend uitgeval het, sou bestem wees om in latere eeue algaande ' $n$ steeds belangriker invloed op SuidAfrika uit te oefen. Vandag as leier van die Westerse moondhede (waaraan Suid-Afrika ook behoort) is die Verenigde State van Amerika 'n transkontinentale reus van sowat 180 miljoen inwoners en is sy invloed op SuidAfrika in resente jare so opvallend dat ons bykans elke week daaromtrent in nuusblaaie en tydskrifte lees, of op die radio daarvan hoor.

Tog is verbasend min bekend oor hoe dit gebeur het dat Amerika wat so ver van Suid-Afrika geleë is, SuidAfrika se ontwikkelingsgang in so ' $n$ mate beïnvloed het. ${ }^{1}$ ) Dit is die probleem wat ons nou kortliks wil bespreek. Dit is 'n moeilike probleem, die invloed van een land op 'n ander; veral waar ons ook voor die probleem van die deurvloeiing van idees te staan kom, asook die stille, deurlopende invloed wat die teenwoordigheid van Amerikaners op die ontwikkeling van ons land gehad het. Ons het ook min riglyne van wetenskaplike presisering en sintese om ons hierin te help. Ek deel met u dus tege- 
lyk die vreugde van ontdekking en die onsekerheid van die ontdekker. Enige nuwe lig moet verwelkom word, selfs in die vorm van hierdie kort en vlugtige oorsig. Ek hoop dit sal ons kan help om die besonder betekenisvolle Amerikaanse beleid teenoor Suid-Afrika vandag beter te begryp.

II

Voordat ons oorgaan tot 'n breë historiese oorsig van die punte van kontak tussen die Verenigde State van Amerika en Suid-Afrika, moet ek my vernaamste uitgangspunte meedeel. Die uitgangspunte moet as riglyne dien by die vertolking van soveel uiteenlopende punte van kontak oor soveel jare.

Met my eerste uitgangspunt, meen ek, sal ons almal saamstem. Dit is dat as gevolg van 'n sameloop van buitengewoon gunstige omstandighede die Verenigde State 'n vroeë voorsprong in sy ontwikkelingsgang teenoor SuidAfrika behaal het. Die V.S.A. het daarin geslaag nie alleen om die voorsprong te handhaaf nie, maar om dit met rasse skrede steeds verder te vergroot. Omdat albei lande produkte is van Wes-Europese ontdekking en kolonisasie en in sekere opsigte soortgelyke probleme ondervind het, kan daar ook in die ontwikkelingsgang van albei lande soortgelyke tendense onderskei word. Dit was dus moontlik vir Suid-Afrika om te leer uit die vroeëre en rypere ervaring van die V.S.A. op velerlei terreine van die lewe. Omgekeerd, kon die V.S.A. maar weinig leer uit ons ervaring. Gevolglik is die geskiedenis van kontakte grotendeels die relaas van die invloed van Amerikaners en Amerikaanse instellings op Suid-Afrika.

My tweede uitgangspunt sluit hierby aan, nl. dat die V.S.A. nog nooit staatkundige beheer oor Suid-Afrika of dele daarvan uitgeoefen het of probeer uitoefen het nie. Daar was handelsverkeer, daar was walvisvangs langs ons kuste, daar was sendingwerk onder ons naturelle, daar was opvoedkundige, godsdienstige en wetenskaplike be- 
invloeding, daar was tegniese en finansiële leiding in verband met mynontwikkeling, daar was die invloed van Amerikaanse staatkundige denkbeelde, daar was belangstelling in die V.S.A. in literatuur oor Suid-Afrikaanse aangeleenthede en omgekeerd. Die rol wat die V.S.A. gespeel het, raak in die reël nie vername hoofstrominge in ons geskiedenis nie. Dit raak egter soveel en so 'n verskeidenheid van terreine oor soveel jare dat die totale uitwerking van Amerikaanse invloed op Suid-Afrika nieteenstaande die afwesigheid van politieke beheer wel deeglik in ag geneem moet word.

My derde uitgangspunt hang met die vorige saam. Dit is dat in sowel die V.S.A. as in Suid-Afrika die algemene oorsese, en veral koloniserende, bedrywighede van Engeland verseker het dat die Engelse taal, instellings en gewoontes stewig wortel geskiet het. Hoewel miljoene vandag nog ander tale besig, is in die V.S.A. Engels vroeg reeds as die enigste amptelike taal aanvaar. In SuidAfrika is Engels een van twee amptelike tale; wat blankes betref, 'n minderheidstaal en wat verkeer na buite betref, die internasionale taal. Sedert die dae van die Amerikaanse Patriotte en die Kaapse Patriotte was Engels die kommunikasiemiddel tussen Suid-Afrikaners en Amerikaners, tussen Suid-Afrika en Amerika - mondeling, skriftelik en in druk. Engelstalige literatuur oor SuidAfrika is dus direk, sonder tussenkoms van 'n vertaler, in die V.S.A. gelees. En daar is vroeg reeds heelwat in die V.S.A. oor Suid-Afrika gelees. Vanselfsprekend het die paralelle ontwikkelingsgang van die blanke kolonies en sy nie-blanke buurman belangstelling gaande gemaak.

Waar daar identiese, of baie dieselfde, kerkgenootskappe, sendinggenootskappe, sosiale verenigings en opvoedkundige instellings in albei lande ontstaan het, het natuurlikerwys heelwat inligting uit Suid-Afrika na Amerika gevloei. Omdat dié inligting in Engels opgestel was en langs bekende kanale gekom het wat vertroue ingeboesem het, is dit in Amerika dikwels op onkritiese wyse 
aanvaar as die volle waarheid oor Suid-Afrika. Menings en inligting oor Suid-Afrika in ander tale as Engels is selde onder Amerikaners se aandag gebring. Die vorming van die Amerikaanse openbare mening oor Suid-Afrika is dus in baie gevalle aangehelp deur filantropiese kritici, in Suid-Afrika en Engeland, van die blanke kolonistestandpunt.

Verder is toestand in Suid-Afrika gewoonlik vertolk in terme van oppervlakkige ooreenkomste tussen die twee lande. Kontakte met Suid-Afrika was heeltemal oorwegend uit die noordelike Amerikaanse state, waar min negers was en waar die houding teenoor nie-blankes gekondisioneer is deur die V.S.A. se eie negerprobleem. Gevolglik is Suid-Afrikaanse rasseverhoudings dikwels deur 'n bril bekyk wat 'n verwronge beeld voorgehou het. In die V.S.A. het die Noorde se liberale rassebeleid teenoor die neger geseëvier, en is die Suide al hoe meer in verhouding tot die Noorde verswak. Wat die Rooihuid betref, is hy mettertyd weerloos teruggedruk in beperkte reserwes as 'n hopelose klein minderheidsgroep. In SuidAfrika, aan die ander kant, is die Bantoe in 'n onvergelykbaar sterker magsposisie gelaat. Op 'n een-man-een-stemgrondslag sou hy die blanke maklik kon oorheers. Die basiese verskille in rassetendense tussen die V.S.A. en Suid-Afrika is dikwels deur die Amerikaner oor die hoof gesien. By gebrek aan betroubare inligting oor die werklike toestande in Suid-Afrika, is ligtelik aanvaar dat die Amerikaanse patroon ook in Suid-Afrika aan die ontwikkel was.

\section{III}

Gedurende Noord-Amerika se koloniale tydperk het Suid-Afrika min onder die aandag gekom en weinig belangstelling opgewek. In afsondering van mekaar het albei lande in verbete stryd teen hul onderskeie inheemse nie-blanke bevolkings getree. Albei lande het slawe uit Afrika ingevoer. Albei het aan die einde van die sewen- 
tiende eeu Franse Hugenote ontvang. In albei het Nederlanders, tesame met ander Wes-Europeane, hulle gevestig. Albei lande was in Europese koloniale oorloë betrek, of moes daarmee rekening hou dat hulle daarin betrokke kon raak.

In Amerika het Engeland, een van die leidende en snelopkomende koloniale moondhede, teen die helfte van die agttiende eeu 'n oorheersende posisie begin beklee. Die Kaap die Goeie Hoop was weer onder beheerı van die Nederlandse Oos-Indiese Kompanjie, 'n uitgediende en sterwende handelsmaatskappy van die Nederlande, self een van die verswakte en agteruitgaande koloniale moondhede, wat reeds van Europese alliansies afhanklik was om sy houvas op die Kaap te behou.

$\mathrm{Na}$ Noord-Amerika, met talle goeie hawens en bevaarbare riviere en mere, word Europeane aangetrek en is daar ' $n$ snelle natuurlike vermeerdering. So moes die Rooihuide algaande swig voor die blanke getalle en beter organisasie. Die Kaap se onherbergsame kuste, onbevaarbare riviere en die halfwoestyn-binneland verder agter die strategiese hawens, het die blanke reeds nie besonder verwelkom nie. Daarby het die N.O.I.K. na die sewentiende eeu nie blanke emigrasie aangemoedig nie. Geen wonder dan dat die blanke bevolkingsaanwas van die twee lande in sterk kontras tot mekaar staan nie. In 1640 - dus nog voor die stigting van die Kaapse verversingspos - was die blanke bevolking van die Noord-Amerikaanse kolonies 25,000 . Dié getal sou die Kaap nie bereik voor ongeveer die tweede Britse verowering van die Kaap in 1806 nie. 'n Kykie na albei se bevolkingsaanwas gedurende hul koloniale jare illustreer die geweldige Kaapse agterstand. Terwyl daar in 1660 reeds 80,000 blanke Amerikaners was, het die Kaap in 1662 maar 200 gehad. Teenoor cen miljoen Amerikaners in 1743, het die Kaapse vryburgers in 1750 nog maar 5,000 getel.

Vanaf die jare sewentig van die agttiende eeu raak die geskiedenis van die twee lande verder in uiteenlopen de ontwikkelingsbane. Albei kom in opstand teen die 
Europese merkantilistiese gesag wat die belange van die moederland te sterk ten koste van sy kolonies wil bevorder. Teen 1783 verwerf die Amerikaanse Patriotte onafhanklikheid, en daarna word 'n federale republiek onder 'n president ingerig. Buitengewoon geslaagde gebiedsuitbreiding veral suidwaarts en weswaarts vind plaas. Maar die Kaapse Patriotte slaag nie in veel van hulle doelstellings nie. Teen die begin van die negentiende eeu is Engeland, nou die oppermagtige koloniale moondheid, meester van die Kaap.

Toe die V.S.A. as nuwe staat in 1783 in die lewe geroep is, het sy invloed op Suid-Afrika nie lank uitgebly nie. En hierdie invloed het aangegroei van die revolusionêre periode, deur die Groot Trek-tydperk, die minerale-ontdekkings in Suid-Afrika, ons Vryheidsoorloë, tot by die huidige tyd. Dit is 'n onbegonne taak om die historiese betekenis van die talle fasette in al die periodes te probeer aantoon. Ons sal slegs 'n voëlvlug onderneem en hier en daar 'n bietjie nader kennis maak met meer populêre, belangwekkende aspekte.

Die vroegste Amerikaanse kontakte met die Kaap was, net soos dié van ander, vroeëre seevarende moondhede, die besocke wat hulle skepe daar afgelê het op pad na die aantreklike Ooste. Vanaf die aankoms van The Harriet ( 55 ton) in April 1784 in Tafelbaai, het groot getalle Amerikaanse handelskepe en walvisvaarders na en om die Kaap gevaar. Merendeels was dit jong Amerikaners met buitengewone ondernemingsgees wat die monopolie van die Engelse Oos-Indiese Kompanjie nie langer eerbiedig het nie. Hulle sou die Kapenaars tegelyk help om ook die monopolie van die Nederlandse OosIndiese Kompanjie verder te ondermyn. Handelskakels met internasionale koopmanne en handelstede word so gesmee. Dit lei daartoe dat Amerikaanse literatuur na die Kaap gebring word en dat revolusionêre denkbeelde 
aan die Kaap wyer versprei. So word die Kaapse Patriotte verder tot verset aangevuur.

Amerikaanse en Kaapse produkte het mekaar goed aangevul. In ruil byvoorbeeld vir Amerikaanse bewaarde voedsel, hout en touwerk, is ingeskeep Kaapse wyn, aalwyn, huide en velle, asook ingevoerde koffie en tee. Die funksie wat die Amerikaanse handelskepe vervul het gedurende die oorloë van die Franse Revolusie en van Napoleon was dié van neutrale vragvaarders wat hoognodige artikels en produkte aan die Kaap voorsien het. Onder aansporing van die Amerikaanse voorbeeld op die gebied van walvisvangs, is ondernemende Kapenaars deur die N.O.I.K. toegelaat om nou ook die walvisvangs te beoefen. Eers deur die N.O.I.K., en daarna deur die magtige Britse vloot, is tevergeefs probeer om die ywerige Amerikaners uit die waters om Suidelike Afrika te weer. Inderdaad het die Kaap nou 'n vername stcunpunt geword vir Amerikaanse walvis- en robbevangers wat die suidelike oseane deurkruis het.

Amerikaanse handels- en seevaartbelange is in so 'n mate geraak, dat die regering van die V.S.A. in 1799 besluit het om 'n konsul in Kaapstad te benoem. John Elmslie van Philadelphia het die volgende jaar die pos aanvaar. Onder sowel die Britse as die Bataafse besture het Elmslie ook as handelaar, en op sosiaal-kulturele terrein, 'n mooi bydrae tot die Kaapstadse samelewing gemaak.

Waar Suid-Afrika tevore as ' $\mathrm{n}$ feitlik totaal onbekende deel van Donker Afrika ('n oord van swart negers) aangesien is, kon heelwat meer inligting oor Suid-Afrika nou na die V.S.A. deurvloei. Die inligting was egter eensydig en het beperkte kringe veral in die Noordelike kusstate van die Verenigde State bereik, waar min begrip vir Kaapse rasseprobleme bestaan het.

Laat ons aanhaal uit een van die eerste werke oor die Kaap wat in die Verenigde State gepubliseer is. 'n Amerikaanse skeepskaptein, Benjamin Stout, het in 1796 op die kus van Kaffrarië skipbreuk gely en toe die vol- 
gende jaar vir John Adams, „President of the Continenta Congress of the United States of America", versoek om hom te interesseer ten behoewe van "those wandering children of nature, ... a race of unoffending mortals, long persecuted by those enlightened savages, who, under the appellations of Christians and Dutchmen, settled themselves by violence on the southern promontory". ${ }^{2}$ ) Toe die Amerikaanse uitgawe van die eerste band van John Barrow se eensydig-filantropiese reisbeskrywing in 1802 in New York verskyn, het tendensieuse inligting oor SuidAfrika verder aangegroei. In dieselfde filantropiese trant het Amerikaanse sendingtydskrifte hul lesers oor beweerde wandade deur die Kaapse boere ingelig. In die Panoplist kon Amerikaners uit 'n verslag van die Londense Sendinggenootskap die volgende woorde lees: „The Boors shewed themselves to be sworn enemies to us; backbitings, blasphemies, and threatenings were brought daily to our ears... The Boors tried to seduce the Hottentots into drunkenness and to corrupt their minds to debelieve (sic) the word of God, despise Christ". ${ }^{3}$ ) By gebrek aan ander inligting, het sekere kringe in Amerika heel aan die begin van die negentiende eeu begin glo dat die Afrikaanse boere die nie-blankes veronreg en onderdruk.

Toe Engeland die Kaap in 1806 beset, het die Amerikaanse handelaars en seevaarders ook met 'n al hoe meer beperkende Britse beleid te kampe gekry. Amerikaanse handelskepe is by die Kaap aangehou nog voordat die V.S.A. gedurende 1812 tot 1815 in oorlog met Engeland betrokke geraak het. Met die Handels- en Seevaartkonvensie van 1815 tussen die twee moondhede word Amerikaanse handelsverkeer met die Kaap uitdruklik verbied.

V

Kort voor die Groot Trek is Amerikaanse kontakte met Suid-Afrika op verskeie terreine hervat. Die V.S.A. was toe reeds 'n vinnig opkomende land waarvan die 
blanke bevolking in 1820 meer as 73 miljoen, in 1830 meer as $10 \frac{1}{2}$ miljoen, en in 1840 byna $14 \frac{1}{4}$ miljoen getel het. Teen 1834 het in die Kaapkolonie nog maar slegs sowat 65,000 blankes gewoon, wat gedeeltelik as gevolg van die Groot Trek besonder stadig aangewas het tot 140,000 in 1854 . Groot veranderinge op baie gebiede in 'n nuwe tyd het egter vir Suid-Afrika voor die deur gestaan. Toe Amerikaanse skepe wat nog altyd om die Kaap na die Ooste gevaar het, nou toegelaat is om hul handelsbetrekkinge met Suid-Afrika te hervat, sou hulle 'n vername plek verwerf in die sneller ontplooiing van die beperkte koloniale gemeenskap aan die suidpunt van Afrika. Amerikaners sou 'n stukrag verleen aan die ontwikkeling van ons oorsese handel asook ons landbou en veeteelt, soos byvoorbeeld deur die verskaffing van deeglik uitgetoetste ploeë. Ook sou hulle feitlik onmiddellik op vele ander terreine die lewe in Suidelike Afrika beïnvloed.

Met die steeds sterker vertoë om 'n groter mate van seggenskap in die bestuur van hul land te verkry, het die Kaapse koloniste die Amerikaanse voorbeeld voor oë gehou. Gedurende 1830 tot 1831 het John Fairbairn in The South African Commercial Advertiser geskryf dat die koloniste die V.S.A. as hul model moes neem. Die bekende Amerikaanse kreet "No taxation without con sent" is deur hom aangehef. Toe ander nuusblaaie in Kaapstad en Grahamstad opgerig is, is daar pogings aan gewend om aan die Kaapse politieke aspirasies 'n duide liker vorm te gee. Uit Amerikaanse nuusblaaie is nou ge redelik nuus oorgeneem. Die werking van die Amerikaan se republikeinse instellings is met duidelike belangstelling gadegeslaan.

Britse en Amerikaanse filantropiese organisasies het nou met mekaar geskakel. So het dr. John Philip bekendheid verwerf in Noord-Amerika en is aan hom in 1819 die doktorsgraad deur Columbia-Universiteit in New York-stad verleen. In 1835 het die American Board of Commissioners for Foreign Missions se eerste sendelinge in Suid-Afrika aangekom om eers die Matabeles en later 
die Zoeloes te bearbei. Onder hulle geledere was miskien die bekendste Amerikaner in ons geskiedenis, eerw. Daniel Lindley. As Presbiteriaan het hy skitterend in die bresse getree toe die Voortrekkers geen predikant kon kry nie. Lindley het 'n stempel op die geestelike lewe van die Voortrekker afgedruk toe hy die hele Voortrekkerland as sy gemeente gehad het. Daarby het hy die noordwaartse trek in Suid-Afrika teen die agtergrond van die Amerikaanse weswaartse uitbreiding gesien. Vir Lindley was die oorwinning van die Voortrekkers op 1 Desember 1837 reeds in sig. Net so onvermydelik as wat die Amerikaanse koloniste na die weste die weerstand van die Indiane verbreek het, net so min kon enige gesag die Voortrekkers verhinder om Suid-Afrikaanse inboorlinge te oorrompel. Die vroegste Amerikaanse sendelinge het 'n belangrike rol gespeel in die kerstening van die inboorlinge in SuidAfrika en dus ook in die verspreiding van die Westerse beskawing. Die talle briewe en joernale wat hulle na Amerika gestuur het, het belangrike inligting oor SuidAfrika verskaf. Baie uittreksels daaruit is in die Missionary Herald gepubliseer. So is volledige, akkurate feite byvoorbeeld oor die stryd tussen die Voortrekkers en die Zoeloes, aan sendingbelangstellendes in Amerika aangebied. Vanselfsprekend was die menings uit 'n sendingstandpunt, maar 'n gebalanseerde sendingstandpunt.

Hierdie sendingberigte was 'n korrektief op ander werke wat in dieselfde tyd in Amerika verskyn het en wat sterk filantropies gekleurd was. 'n Gewilde reisver. haal soos Reynolds se wêreldreis van die fregat Potomac het die rassebeleid van die Afrikanerboer veroordeel. Die Xhosa word hierin beskryf as hardwerkend, mooi van postuur en intelligent. „But oppression and wrongs have driven them to predatory acts of retaliation", word verklaar, ,.... and have involved them in numerous conflicts with the colonists, steeping their native soil in blood, which only enriches it for the benefit of the everencroaching whites". ${ }^{4}$ )

Die hervatting van handelsbetrekkinge tussen die 
V.S.A. en Suid-Afrika het die aanstelling van die tweede Amerikaanse konsul meegebring. Dit was Isaac Chase, 'n Amerikaanse koopman uit Massachusetts, wat 'n bedrywige lewe in Kaapstad vanaf 1835 gevoer het. Sy opvolger was Gideon S. Holmes, 'n skeepskaptein, wat hom later as handelaar in Kaapstad gevestig het en 'n florerende firma opgebou het wat tot na die ontdekking van diamante sou voortbestaan.

Holmes is een van talle onbekende Amerikaners wat die Kaapkolonie as sy tweede vaderland aangeneem en groot kommersiële ondernemingsgees geopenbaar het. Ons kan slegs enkele voorbeelde noem. Hy was in bevel van die Amerikaanse brik, die Levant, wat republikeinse Port Natal in 1841 besoek het en op die sandbank voor die baai gaan vassit het; hy het sy jong broer voor sy oë in die see sien verdrink. Tien jaar later voer hy ys in, gesaag uit die mere van Nieu-Engeland en deur die trope na Kaapstad verskeep. Holmes land 178 ton ys wat hy uit 'n spesiaal opgerigte yshuis aan Kapenaars teen $2 \frac{1}{2} d$. per pond verkoop en teen $1 \frac{1}{2} \mathrm{~d}$. per pond aan kaartjiehouers. Kort daarop adverteer hy weer dat hy Amerikaanse fietse in St. Georgestraat te koop aanbied. In hierdie tyd adverteer Holmes ook Amerikaanse oesmasjiene, maar sy Amerikaanse ondernemingsgees laat dit nie daarby nie. Op 30 Oktober 1852 lees ons in The South African Commercial Advertiser: ,.... an interesting trial will take place on the farm of L. van der Byl, Esq., of Eerste River, of two Reaping Machines, one of Garrett's, imported from Scotland, for Mr. van der Byl, and the other one of Hussey's, imported by Capt. Holmes, United States Consul, from America. This being the first time the respective merits of these have been tried in the Colony, it has excited great interest, and a very large attendance is expected". Voor 'n baie groot aantal boere van heinde en ver, en in die teenwoordigheid van luitenant-goewerneurs Darling en Pine, het die kompetisie op 5 November getoon dat, terwyl die Skotse masjien die beste gevaar het op harde grond Hussey's Patent American Reaping 
Machine op 'n los, sanderige bodem die wenner was. Aangesien die Eersterivier bekend is vir sy sanderige grond, moet mens tot die gevolgtrekking kom dat dit 'n eufemistiese manier was waarop die Commercial Advertiser meegedeel het dat die Amerikaner die Skot uitgestof het.

Kapt. Holmes het hiermee nie opgehou met sy pogings om te bewys dat ook ander Amerikaanse fabrikate alle andere kan klop nie. Op dieselfde Vrydag 5 November 1852, vertrek die vinnige Amerikaanse skip, met sy goeie Suid-Afrikaanse naam, die Springbok, van Port Elizabeth na Kaapstad, tesame met die Majesty en die Annie, slegs een uur na mekaar. Ook hier moes die Commercial Advertiser aankondig dat die Amerikaanse Springbok (waarvan Holmes die agent was) die Majesty met twee dae geklop het, terwyl die Annie nog nie eers opgedaag het nie.

Dat Amerikaanse literatuur gewild was blyk o.a. uit 'n advertensie dat ,a large assortment" van Uncle Tom's Cabin in Kaapstad aangekom het en in verskillende edisies van $2 \mathrm{~s}$ tot $10 \mathrm{~s} 6 \mathrm{~d}$ te koop is. Met 'n tipies Amerikaanse sin vir die regte geleentheid, word bygevoeg „also a large assortment of new music; including Uncle Tom's Cabin Polka". Ander Amerikaanse boeke verder geadverteer toon watter titels as geskik vir die Kaapse publiek beskou is: Spark's American Biography (in 10 dele), Indian Captivities, The American Gardener, Complete Farmer, Yankee Notions en Marshall's Life of Washington. En dan twee praktiese werke wat die Amerikaanse vroulike ideale weerspieël: Woman as she should be en The American Frugal Housewife.

\section{VI}

Waar Amerikaners voor die ontdekking van minerale en grootskaalse ekonomiese ontplooiing van Suid-Afrika reeds 'n klein maar treffende rol in die ontwikkeling van ons land gespeel het, sou hulle sedert die laaste drie dekades van die negentiende eeu 'n al meer prominente aandeel verkry. Dit behoort geen verwondering te wek 
nie. Die V.S.A. was in hierdie jare 'n industriële reus, en baie Amerikaners het reeds 'n ryke ervaring van baie ondernemings opgedoen. Amerikaanse myningenieurs om net een groep te noem - neem gevolglik dikwels leiding in die ontginning van diamante en goud in SuidAfrika.

Ons kan hier weer enkele name noem. In die tydperk van die diamantdelwerye het die Amerikaner Babe ' $n$ wiegvormige uitsifmasjien ontwerp, wat as "Baby" bekend geword het. Gardner F. Williams het Cecil Rhodes se algemene bestuurder van die De Beers Diamond Mines geword. Hy is ook bekend as die skrywer van The Diamond Mines of South Africa (New York, 1902) en is in sy pos deur sy seun Alpheus F. Williams opgevolg. ${ }^{5}$ ) John Hays Hammond is seker een van die bekendste Amerikaners uit hierdie tyd. Hy was een van die "Reformers" wat deur die Transvaalse hof ter dood veroordeel is. Sy vonnis is versag tot tronkstraf en later is hy na betaling van ' $n$ boete vrygelaat. ${ }^{6}$ ) Waar Hammond baie nou by Rhodes en sy planne ingeskakel het, is ' $n$ ander Amerikaanse ingenieur, E. Woodford, deur die Transvaalse regering as eerste Goewermentsingenieur aangestel. Woodford het 'n doeltreffende grondslag van mynwetgewing in die Transvaal gelê, wat gesonde ontwikkeling moontlik gemaak het.

'n Amerikaner wat op ander gebiede reuse-ondernemings opgebou het, is Isidore Schlesinger wat in 1896 na Suid-Afrika gekom het.

Teen die uitgang van die negentiende eeu is duisende Amerikaners in Suid-Afrika, en by uitstek op die Rand, gevestig. Toe die Tweede Vryheidsoorlog uitbreek, raak baie Amerikaners betrokke en veg aan albei kante. Die myningenieurs en finansiers begunstig dikwels die Britse kant, en baie ander veg weer aan Boerekant, byvoorbeeld kapt. J. Hassell, bevelvoerder van die sogenaamde „American Scouts".7) Die Amerikaanse konsulêre verteenwoordigers het Britse belange behartig en selfs hulle was verdeel oor die oorlog. 
Amerikaanse belange is in allerlei opsigte geraak. Britse kruisers het op Amerikaanse goedere op pad na Lourenco Marques beslag gelê en Amerikaanse muile en perde is van Ned Orleans na Suid-Afrikaanse hawens vir die Britse leër verskeep. Honderde jong Amerikaners wat as diereversorgers na Suid-Afrika gekom het, het in die Britse leër beland. Alhoewel die meerderheid van die Amerikaanse volk wat in Suid-Afrika belang gestel het, pro-Boer was, het daar meer Amerikaners aan Britse as aan Boerekant geveg. Daar het in Amerika 'n groot aantal boeke oor die Tweede Vryheidsoorlog verskyn. As gevolg van die Oorlog is Suid-Afrika, wat die gemiddelde Amerikaner betref, op die wêreldkaart geplaas. In die V.S.A was wydverspreide pro-Boerverenigings. Die Oorlog het ook ' $n$ belangrike rol in die Amerikaanse buitelandse beleid gespeel. Die Amerikaanse regering was oorwegend pro-Brits en kon, weens die hooglopende gevoelens in Amerika, nie die grens tussen Alaska en Kanada op daardie stadium vasstel nie, maar was verplig om dit jarelank uit te stel. $^{8}$ )

\section{VII}

Laat ons nou ons voëlvlug voltooi deur na ons eie tyd te kyk.

Vandag is die wedersydse beïnvloeding groter as ooit tevore. Oor die eeue het veranderings in die verhouding tussen die V.S.A. en Suid-Afrika ingetree. Suid-Afrika se drie miljoen blankes het 'n belangrike betekenis gekry in die formulering van die Amerikaanse buitelandse beleid. Gevolglik kom Suid-Afrika nou in die politieke trefkrag van die V.S.A. Verder word daar in resente jare van die bestaan van Afrikaanse geskrifte met die Afrikaner se standpunt kennis geneem. Amerikaanse diplomate leer Afrikaans. 'n Stelselmatige studie van toestande word persoonlik deur Amerikaanse geleerdes in Suid-Afrika gemaak.

Die weë van die twee lande het ver uitmekaar geloop Die V.S.A. het oplossings vir sy probleme in ander rigtings 
gaan soek as ons in Suid-Afrika. Terwyl in Noord-Amerika die integrasie van die Witman en die Neger van staatsweë verplig word, word in Suid-Afrika ten opsigte van die Witman en die Bantoe presies die teenoorgestelde staatsbeleid gevolg. In die V.S.A. se strewe om sy leierskap van die Westerse moondhede te behou en om die koue oorlog te wen, staan hy op rassegebied vir feitlik alles waarteen Suid-Afrika gekant is. Die historiese ontwikkeling van die twee lande het dit meegebring. Die mening van vooraanstaande Amerikaners is dat die Suid-Afrikaanse rassebeleid nie alleen immoreel is nie maar ook onverstandig in die huidige wêreld. In die oë van baie Amerikaners is die Suid-Afrikaanse beleid 'n halsstarrigheid wat tot 'n verlede behoort wat lank reeds uitgedien is. En die halsstarrigheid tref hulle ook aan onder blanke Amerikaners in hul eie Suide, waar hulle oortuig is dat die ou uitgediende orde spoedig deur 'n nuwe vervang sal word. Hulle glo dat die regering in Suid-Afrika, ook die Suid-Rhodesiërs, sterk in hul verset teen 'n liberaler orde en sien die drie miljoen blankes in Suid-Afrika vandag as een van die lastigste probleme vir die V.S.A. Daar kan afgelei word dat dit hulle mening is dat wanneer die Witkolle in Suidelike Afrika verdwyn, die probleem ook sal verdwyn.

Suid-Afrika verset hom al jare lank teen die V.V.O. Die rassebeleid van Suid-Afrika en selfs die blote teenwoordigheid van die Witman in 'n magsposisie in SuidAfrika beweeg die Afro-Asiatiese lande vandag om hul oorwig in die V.V.O. te gebruik om Suid-Afrika onder sy huidige bewind aan die grootste moontlike druk bloot te stel sodat die bewind omvergegooi kan word. Suid-Afrika se suksesvolle verset sou die V.V.O., wat reeds deur gebeurtenisse in die voormalige Belgiese Kongo ernstig aangetas is, 'n nekslag kon toedien. Dit is die beleid van die V.S.A. om die V.V.O. staande te hou as 'n instrument van wêreldvrede en wêreldorde. Daarom wil die V.S.A. nie toelaat dat die komende stryd die wêreldliggaam sal laat ontbind nie. Hierdie Amerikaanse strewe hou klaarblyk- 
lik gevaar vir Suid-Afrika in. Die moontlikheid bestaan dat die staatkundige en militêre mag van die Amerikaanse reus nou vir die eerste keer teen Suid-Afrika onder sy huidige bewind ter ondersteuning van die V.V.O. aangewend kan word. Alhoewel Suid-Afrika in 'n baie sterk ekonomiese en strategiese posisie verkeer, is geen kentering nog in sig nie.

Prof. Vernon McKay, 'n gesiene Amerikaanse geleerde en internasionale verteenwoordiger van sy land, verklaar: "We must attune ourselves to this revolutionary spirit in Africa and Asia and view it as affirmatively and sympathetically as we can. If we fail in the effort, we may find our present system of international security collapsing all around us within the next decade". ${ }^{9}$ ) Die vrae wat verrys, is hoe ver kan die V.S.A. met die revolusionêre gees in Afrika saamgaan, en indien hy die hele pad saamgaan, sal dit inderdaad die behoud van sy stelsel van internasionale veiligheid verseker? Prof. McKay skryf verder dat Suid-Afrika en Portugal se beleidsrigtings ",can only lead to trouble for Africa, for themselves, and for the rest of the world. No doubt other policies would also create problems, but Portugal and South Africa will have to move with the trend of the times sooner than they think. Much will depend on how and when they reconcile themselves to this fact, and American diplomacy ought continually to impress it upon them". ${ }^{10}$ ) Dit is die raamwerk waarin die V.S.A. vandag die toekoms sien en sy beleid daarteenoor bepaal.

Indien die V.S.A. in hierdie rigting met groot beslistheid gaan optree, kan die laat-twintigste eeu as die Amerikaanse eeu in ons geskiedenis bekend word. Dit sal dan volg op die Engelse negentiende eeu, die Nederlandse sewentiende en agttiende eeue, en die Portugese vyftiende en sestiende eeue.

Die toekoms is egter nie die terrein waarop die historikus hom ligtelik moet waag nie. Ek hoop dat $u$ met hierdie kort oorsig van die geskiedenis van die Amerikaans-Suid-Afrikaanse verhoudings, $u$ eie beeld van ' $n$ 
vinnig naderende toekoms sal begin skep, wat $\mathbf{u}$ binnekort self met 'n nuwe hede en 'n nuwe verlede sal kan vergelyk.

C. F. J. Muller.

Universiteit van S.A.

Pretoria.

1) Die mees oorsigtelike algemene werk is die boeiende, maar nie altyd akkurate, Stars and Stripes in Africa deur E. Rosenthal (Londen 1938). Prof. D. J. Kotze het die mees gedetailleerde studies onderneem in sy Die Eerste Amerikaanse Sendelinge onder die Matabeles (Argief-jaarboek vir SuidAfrikaanse Geskiedenis, 13e jrg., I, 1950) en Die Eerste Amerikaanse Sendelinge onder die Zoeloes, 1835-'38 (Arg.-jaarboek vir S.A. Gesk., 21e jrg., I, 1958).

2) Narrative of the Loss of the ship Hercules, .. Londen 1798, pp. i en ii.

3) Panoplist, 1805, p. 416.

4) J. N. Reynolds: Voyage of the United States Frigate Potomac, (New York, 1835), p. 81.

5) $\mathrm{Hy}$ is die skrywer van twee werke: The Genesis of the Diamond, 2 dele (Londen, 1932) en Some Dreams come true (Kaapstad, 1948).

6) The Autobiography of John Hays Hammond, 2 dele (New York, 1935).

7) Kyk A. R. I. Hiley en J. A. Hassell: The Mobile Boer, (New York, 1902).

8) Kyk o.a. J. H. Ferguson: American Diplomacy and the Boer War (Philadelphia, 1939) en The Letters of Theodore Roose velt, uitgegee deur E. E. Morison, dele 2 en 3 (Cambridge, Mass., 1951 vlg.).

9) Africa in World Politics (New York and Evanston, 1963), p. 425.

10) Ibid., p. 420 